\title{
Business Retention and Expansion (BRE) Programs: Preparing a Community Assessment ${ }^{1}$
}

\author{
Henry M. Cothran²
}

\section{Introduction}

A community assessment is a valuable tool for use in economic development programs. The assessment includes all the components of a more traditional socio-economic profile of a community, as well as an inventory of the programs and services available to businesses, existing infrastructure, a history of the community, and information on the community's quality of life. Such an assessment may go even further by examining more broadly both the direction and intensity of change over time. Information from the profile can be used for a variety of purposes, including education, benchmarking, and potentially identifying gaps in resources needed for the retention and expansion of existing businesses. However, the primary purpose for conducting a community assessment is to educate yourself, your program partners, visitation team members, and local decision-makers about the community.

This publication is part of a series on establishing Business Retention and Expansion programs (BREs). The publications in this series can be found online at the EDIS website at http://edis.ifas.ufl.edu/topic_series_bre.

\section{What Is a Community Assessment?}

A community assessment can be likened to a snapshot-a picture of the community at a single point in time. Consisting of information about the economic, demographic, infrastructure, quality of life, and history of the community, it draws upon primary information found in community records and other locally assembled data unique to the community, and secondary data typically available from external sources such as state and federal agencies. It is a document designed to meet the information needs of end users, such as those involved in economic development efforts within the community.

\section{How Is the Assessment Used?}

A community assessment has three broad uses: a tool for educating the business retention and expansion (BRE) program staff, the BRE partners and the BRE team members; a source for baseline socio-economic, infrastructure, services and quality of life data for the community; and as the background for the development of a retention and expansion strategy.

As an education tool, the assessment provides the information necessary for BRE staff to become knowledgeable about the community, its history, and its strengths and weaknesses. The assessment should also be used to educate the BRE partners, with a particular emphasis on those areas where the partners could focus efforts for positive change. And it should be required reading for the BRE visitation team so that they, too, are intimately familiar with the facts about the community.

1. This document is FE659, one of a series of the Food and Resource Economics Department, Florida Cooperative Extension Service, Institute of Food and Agricultural Sciences, University of Florida. Original publication date January 2009. Reviewed January 2012. Visit the EDIS website at http://edis.ifas.ufl. edu.

2. Henry M. Cothran, Associate In, Food and Resource Economics Department, Florida Cooperative Extension Service, Institute of Food and Agricultural Sciences, University of Florida, Gainesville, FL. 
Since the assessment contains significant information about the socio-economic status of the community, the document can provide base-line data for economic development projects and as the basis against which change is measured. The inventory aspect of the assessment makes the document a useful tool in educating the business community about "what is" and the public about "what isn't" available in the community that impacts the retention and expansion of existing businesses.

Taken together, the information in the assessment provides a starting point for an analysis of the community's strengths, weaknesses, opportunities, and threats. Thus the document becomes the basis for developing a strategic retention and expansion plan-by identifying gaps in programs and services, the community can develop appropriate plans to address these gaps so that existing businesses are retained, and, where possible, expanded.

\section{What Information Is Included in the Assessment?}

Community assessments are often rather sterile documents consisting primarily of tables, charts, graphs, and lists that describe the community, but there is no one "right" way to compile and present the information. How these data are grouped for presentation depends on the way the assessment is to be used by the community and the frame of reference of the compiler (people tend to view, and thus compose, the information from their unique backgrounds and training as well as the level of comfort they have in dealing with the data they are compiling). A good rule of thumb for organizing the content and presentation of a community assessment would be to think from the end user's perspective. For example, is the most important information the first thing the user will see? Is the information up-to-date? If the user wants additional information, does the assessment contain links to other data sources or local contacts?

Assessments prepared for community economic development contain broad common themes that may be considered required content. These broad thematic areas include information on the community, an inventory of community assets, programs and services available for businesses, quality of life information, and socio-economic characteristics of the community and its workforce. Furthermore, most assessments share a common approach to the presentation of this information by focusing primarily on charts, graphs, and tabular forms to display information about the community relevant to the the purposes of the document.
Narrative content is kept to a minimum and is usually limited to things like a description of the community and its history. In the International City/County Management Association's publication Business Attraction and Retention: Local Economic Development Strategies (Kotval, Mullin, and Payne 1996), a number of essential content areas are identified and described. A similar set of content areas may be found in the publication Developing a Community Profile (Moss and Grunkemeyer 1996) published by the Ohio State University Cooperative Extension Service. The suggested content areas are described below. The detail provided here for each content area is not exhaustive-rather, it is intended to give an idea of the types of content for each broad category.

\section{The Community}

As mentioned previously, many assessments contain a brief history of the community. Narratives providing community context-in-brief for the assessment's end users should describe the characteristics of the community that make it unique. This section could also include the key leadership positions in the community and appropriate official contact information for these positions. A map of the community showing its location relative to the rest of the state together with major access routes into the community may serve well here. Some include a table showing the mileage and travel time to nearby major metropolitan areas.

\section{Quality of Life}

This section of the assessment may contain a variety of types of information, including education access, health care facilities and the number of providers, safety statistics, and recreational and cultural opportunities. Shopping access, housing availability, and cost of living data should be included as well.

\section{Population}

A table showing the population change over time should be included. This table could include comparable statewide information and a breakout of the population by age group, with a particular emphasis on the size of and change in the working-age population.

\section{Labor Force}

What is the current labor force availability? What percentage of the workforce lives in the community? What is the average commute-to-work time for each segment of the community's workforce? What is the size, quality, and participation rate of the working age population? What are the employment and unemployment rates for 
the community? What does the community provide that encourages labor-force participation? Available workforce from outside the community but within the laborshed is another useful statistic that would be appropriately placed in this section of the assessment.

\section{Local Government}

What services does local government provide? If appropriate, identify contact points for permitting and regulatory agencies that existing and potential businesses may need to contact. If not presented in a separate section, local and state income, property, business, and other taxes may be included here.

\section{Utilities and Services}

List the local utility providers for all available utilities and services. When listing communications services, be certain to include details on the availability of internet services and broadband. When listing available utilities, include appropriate capacity information.

\section{Commercial Site Inventory}

Provide a listing of existing land and facilities zoned for commercial operations. If the community has an industrial park, provide information on available facilities and the infrastructure serving the park.

\section{Transportation}

List the nearest airport with scheduled commercial airline service and the airlines serving the area. Include rail and port services if they are available. Identify federal, state, and local highways that serve the community as well as the distance from the community to the nearest federal and state roads.

\section{Training Resources}

This section of the assessment should contain a list of the high schools, vocational/technical schools, and colleges and universities that serve the community. In addition, contact information for the local Workforce Development Board should be included.

\section{Access to Capital}

Compile and include a list of local financial institutions and programs that serve the business community. If the community offers economic development financing packages or assists in the application process for financing, that information should be included in this section.

\section{Contact Information}

A name, organization, address and telephone, and electronic contact information should be provided at the beginning of the assessment. If the economic development organization or community has a website, the URL should be provided.

\section{Where Do I Find Information for the Assessment?}

All of the information typically contained in an assessment can be found from secondary sources, such as the Census Bureau, and state labor and revenue agencies, or from information compiled in your local community by city or county government agencies. Information on the history of the community may be found in the local public library or from the community historical society. Useful Federal websites include "the big three" bureaus for data pertinent to community assessments: the Census Bureau (http://factfinder.census.gov/home), Bureau of Labor Statistics (http:// stats.bls.gov/), and Bureau of Economic Analysis (http:// www.bea.gov/). All states have similar sites for state-specific data. Search state Departments of Commerce or Economic Development and Departments of Labor, particularly Labor Market Information pages, for detailed local data. In Florida, most of the needed state information for your community assessment can be found online at the websites for Labor Market Information (http://www.labormarketinfo. $\mathrm{com} /$ ) or the Florida Research and Economic Database (http://fred.labormarketinfo.com/).

\section{Conclusion}

A community assessment is an integral part of a community's business retention and expansion program. It can be as basic or complex as you want it to be. It may be focused on specific economic data and trends or oriented to social conditions, depending on the nature and goals of your BRE program. The assessment serves first and foremost as a tool to educate the BRE staff, visitation teams, and program partners. It is also useful for identifying economic and social gaps in the community, thus serving as one basis for documenting the need for the BRE program. Regardless of how it is structured, it must be accurate, informative, and used.

\section{References}

Moss, M. and B. Grunkemeyer (1996). Developing a Community Profile. CDFS-1502-98, The Ohio State University, Columbus, $\mathrm{OH}$. 
Kotval, Z., J. Mullin, and K. Payne, (1996). Business Attrac-

tion and Retention: Local Economic Development Efforts.

International City/County Management Association,

Washington, D.C. 